\title{
PELATIHAN SISTEM PENGENDALIAN MANAJEMEN DAN LEADERSHIP BAGI ORGANISASI INFORMAL DI KOTA PALEMBANG
}

\author{
Leriza Desitama Anggraini1), Endah Dewi Purnamasari2), Faradillah ${ }^{3)}$
}

\author{
1)Program Studi Akuntansi Fakultas Ekonomi Universitas Indo Global Mandiri \\ 2)Program Studi Manajemen Fakultas Ekonomi Universitas Indo Global Mandiri \\ 3)Program Studi Sistem Informasi Fakultas Ilmu Komputer Universitas Indo Global Mandiri \\ Jalan Jenderal Sudirman No. 629 Km. 4 Palembang Kode pos 30129 \\ Email : leriza@uigm.ac.id ${ }^{1}$,endahdps@uigm.ac.id2),faradillah.hakim@uigm.ac.id ${ }^{3}$ )
}

\begin{abstract}
ABSTRAK
Pelatihan ini dilakukan dengan tujuan untuk memberikan pengetahuan keorganisasian dalam menjalankan suatu organisasi melalui sistem pengendalian manajemen dan leadership. Sistem pengendalian manajemen berguna untuk menentukan keberhasilan dan pengembangan yang berkelanjutan, maka suatu organisasi saat ini harus memiliki sistem yang baik dan tenaga kerja yang berkualitas. Organisasi yang baik hendaklah mempunyai anggota-anggota yang memiliki pengetahuan keorganisasian yang memadai. Permasalahannya masih banyak anggota organisasi terutama organisasi informal di Kota Palembang yang notebenenya belum memiliki sistem manajemen organisasi yang baik sehingga masih kurang memahami pengetahuan keorganisasian. Maka dari itu, perlu adanya pelatihan sistem pengendalian manajemen dan leadership menggunakan metode komunikasi kelompok agar dapat lebih dipahami. Berdasarkan hasil kegiatan pelatihan ini tingkat pemahaman peserta mengalami peningkatan, terbukti dari hasil diskusi kasus serta pemecahan masalah dan pencarian solusi yang dipaparkan oleh peserta sudah sesuai dengan materi yang disampaikan sebelumnya. Pentingnya pelatihan ini bagi organisasi informal karena dengan adanya pelatihan ini akan memberikan value added bagi pengurus dan anggota organisasi agar dapat menjalankan organisasinya dengan tertata sehingga dapat mencapai tujuan organisasi dengan baik.
\end{abstract}

Kata kunci: Sistem Pengendalian Manajemen, Leadership, Organisasi

\section{PENDAHULUAN}

Sistem pengendalian manajemen merupakan salah satu alat organisasi yang penting untuk menunjang kinerja optimal dari suatu organisasi. Sistem pengendalian manajemen berguna untuk menentukan keberhasilan dan pengembangan yang berkelanjutan, maka suatu organisasi saat ini harus memiliki sistem yang baik dan tenaga kerja yang berkualitas, sistem yang baik salah satunya adalah sistem pengendalian manajemen yang optimal. Menurut Abdul Halim dkk (2000), Sistem pengendalian manajemen merupakan proses dimana manajer mempengaruhi anggotanya untuk melaksanakan strategi organisasi.

Selanjutkan menurut R.A Supriyono (2000) Sistem pengendalian manajemen adalah sistem yang digunakan oleh manajemen untuk mempengaruhi anggota organisasinya agar melaksanakan strategi dan kebijakan organisasi secara efisien dan efektif dalam rangka mencapai tujuan organisasi, sistem pengendalian manajemen terdiri atas struktur dan proses. Sistem pengendalian manajemen juga menjadi komponen penting dalam literatur akuntansi manajemen, dimana akuntansi manajemen mengarahkan pada manajemen organisasi secara efektif dan efisien.

Sistem pengendalian manajemen memerlukan beberapa faktor-faktor pendukung terutama dari lingkungan internal organisasi, salah satunya adalah anggota organisasi sebagai eksekutor dan basis modal untuk mewujudkan kinerja organisasi yang optimal. Maka dari itu, pengetahuan yang dimiliki oleh anggota organisasi merupakan salah satu faktor penentu keberhasilan suatu organisasi.

Organisasi yang baik hendaklah mempunyaianggota-anggota yang memiliki pengetahuan keorganisasian yang memadai agar dapat mewujudkan tujuan organisasi tersebut. Agar dapat memiliki anggota-anggota yang memiliki pengetahuan keorganisasian yang memadai, organisasi 
harus memberikan pembelajaran organisasi (organizational learning) kepada seluruh anggotanya. Salah satu manfaat pembelajaran organisasi yaitu untuk menurunkan peluang terjadinya pengulangan kesalahan, dimana akan berpengaruh terhadap kinerja organisasi.

Pembelajaran organisasi ini dirasakan sangat penting bagi organisasi-organisasi, salah satunya organisasi informal. Menurut J Winardi (2003), organisasi informal memiliki beberapa ciri-ciri yang membedakan dari organisasi formal, antara lain sebagai berikut:

1. Keanggotaan pada organisasi-organisasi informal dapat dicapai baik secara sadar maupun tidak sadar, dan kerap kali sulit untuk menentukan waktu dimana seseorang menjadi anggota organisasi tersebut.

2. Sifat hubungan antara anggota dan bahkan tujuan organisasi yang bersangkutan tidak terspesifikasi.

3. Organisasi informal dapat dialihkan menjadi organisasi formal apabila hubungan didalamnya dan kegiatan yang dilakukan terstruktur dan terumuskan.

4. Organisasi informal, merupakan kumpulan antar perseorangan tanpa tujuan bersama yang disadari, meskipun pada akhirnya hubungan-hubungan yang tak disadari itu untuk tujuan bersama.

5. Dalam organisasi formal, tiap unsur organisasi mempunyai kedudukan tugas dan fungsi-fungsi yang tegas. sedangkan didalam organisasi informal, kedudukan serat fungsinya tampak kabur.

Berdasarkan penjelasan di atas, dapat disimpulkan bahwa organisasi informal merupakan kumpulan dua orang atau lebih yang terlibat dalam suatu aktifitas serta tujuan bersama yang tidak disadari atau dapat disebut organisasi yang tidak berbadan hukum, seperti contoh organisasi seni dan komunitas kreatif.

Organisasi informal memiliki perbedaan dengan organisasi formal yang notabene memiliki sistem yang jelas didalam menjalankan aktifitas organisasinya. Organisasi informal biasanya memiliki tujuan bersama yang mengikat anggota-anggotanya, namun permasalahannya organisasi informal terbentuk dari persamaan aktivitas saja tanpa dibekali basic organisasi. Sehingga mengakibatkan anggota-anggota organisasi informal kurang memiliki pengetahuan keorganisasian, khususnya organisasi informal yang ada di Kota Palembang. Melihat kebutuhan tersebut, saya dibantu oleh Ikatan Mahasiswa Seni Fakultas Ekonomi Universitas Sriwijaya (IMASFEK) sebagai penyelenggara Pelatihan Sistem Pengendalian Manajemen dan Leadership yang ditujukan untuk organisasi informal. Pelatihan Sistem Pengendalian Manajemen dan Leadeship ini banyak diikuti oleh komunitas penggiat seni dan kreatif di Kota Palembang. Berdasarkan pemaparan tersebut maka diharapkan pengabdian ini dapat memberikan value added serta meningkatkan kinerja bagi organisasi informal di Kota Palembang.

\section{METODE PELAKSANAAN PENGABDIAN}

Permasalahan bahwa anggota organisasi informal masih kurang memahami pengetahuan keorganisasian membawa arti penting untuk melakukan pelatihan sistem pengendalian manajemen dan leadership menggunakan metode komunikasi kelompok. Komunikasi kelompok merupakan komunikasi yang berlangsung antara seseorang komunikator kepada sekelompok orang yang jumlahnya lebih dari dua orang. Karena apabila komunikasai seseorang atau dua orang itu termasuk komunikasi antar pribadi (Effendi, 2003:75). Metode ini dilakukan melalui ceramah sesuai dengan materi sistem pengendalian manajemen dan leadership dilanjutkan dengan diskusi, selanjutnya diberikan pelatihan dalam melakukan pembukuan organisasi, pengendalian internal organisasi dan teknik kepemimpinan. Kegiatan ini dilaksanakan dalam bentuk workshop.

\subsection{Jadwal Pelaksanaan}

Berikut jadwal pelaksanaan kegiatan pengabdian:

1) Lokasi Pelaksanaan

Kegiatan pengabdian ini dilaksanakan bagi organisasi informal di Kota Palembang. Lokasi pelatihan di SD Muhammadiyah Balayudha 6/14 yang beralamat di Jl. Jendral Sudirman Km 4,5 Palembang. 
2) Waktu Pelaksanaan

Kegiatan pelatihan dilaksanakan selama dua hari, terhitung dari tanggal 5 Mei 2018 s.d 6 Mei 2018. Kegiatan pelatihan hari pertama dimulai dari pukul 13.00 s.d pukul 16.00 dan hari kedua dimulai dari pukul 10.00 s.d pukul 16.00. Berikut ini susunan rundown kegiatanpelatihan:

Tabel 1. Rundown Kegiatan Pelatihan

\begin{tabular}{|c|c|c|c|c|}
\hline Hari / Tanggal & Waktu & Kegiatan & Pembicara & Tempat \\
\hline \multirow{5}{*}{$\begin{array}{l}\text { Sabtu / } 5 \text { Mei } \\
2018\end{array}$} & $13.00-13.15$ & Pembukaan & MC & \multirow{5}{*}{$\begin{array}{c}\text { SD Muhammadiyah } \\
\text { Balayudha }\end{array}$} \\
\hline & $13.15-13.30$ & Persiapan Presentasi & - & \\
\hline & $13.30-15.00$ & $\begin{array}{c}\text { Penyampaian Materi } \\
\text { Penyusunan Pembukuan } \\
\text { Akuntansi }\end{array}$ & $\begin{array}{l}\text { Leriza Desitama } \\
\text { Anggraini }\end{array}$ & \\
\hline & $15.00-15.45$ & Sesi Tanya Jawab & $\begin{array}{c}\text { Leriza Desitama } \\
\text { Anggraini }\end{array}$ & \\
\hline & $15.45-16.00$ & Penutupan hari pertama & $\mathrm{MC}$ & \\
\hline \multirow{10}{*}{$\begin{array}{l}\text { Minggu / } 6 \\
\text { Mei } 2018\end{array}$} & $10.00-10.15$ & Pembukaan hari kedua & $\mathrm{MC}$ & \multirow{10}{*}{$\begin{array}{c}\text { SD Muhammadiyah } \\
\text { Balayudha }\end{array}$} \\
\hline & $10.15-10.30$ & Persiapan Presentasi & - & \\
\hline & $10.30-11.30$ & $\begin{array}{l}\text { Penyampaian Materi } \\
\text { Pengendalian Internal } \\
\text { Organisasi }\end{array}$ & $\begin{array}{l}\text { Endah Dewi } \\
\text { Purnamasari }\end{array}$ & \\
\hline & $11.30-12.00$ & Sesi Tanya Jawab & $\begin{array}{l}\text { Endah Dewi } \\
\text { Purnamasari }\end{array}$ & \\
\hline & $12.00-13.00$ & Isoma & - & \\
\hline & $13.00-13.45$ & $\begin{array}{l}\text { Penyampaian Materi } \\
\text { Leadership }\end{array}$ & $\begin{array}{c}\text { Leriza Desitama } \\
\text { Anggraini }\end{array}$ & \\
\hline & $13.45-14.15$ & Sesi Tanya Jawab & $\begin{array}{c}\text { Leriza Desitama } \\
\text { Anggraini }\end{array}$ & \\
\hline & $14.15-15.15$ & $\begin{array}{c}\text { Pelatihan dengan } \\
\text { membentuk Group } \\
\text { Discussion dan } \\
\text { dihadapkan beberapa } \\
\text { kasus terkait materi yang } \\
\text { telah disampaikan }\end{array}$ & Faradillah & \\
\hline & $15.15-15.50$ & $\begin{array}{c}\text { Diskusi Hasil Pelatihan, } \\
\text { Pemberian Saran dan } \\
\text { Rekomendasi }\end{array}$ & Faradillah & \\
\hline & $15.50-16.00$ & Penutupan Pelatihan & $\begin{array}{c}\text { Leriza Desitama } \\
\text { Anggraini }\end{array}$ & \\
\hline
\end{tabular}

\subsection{Tahapan Pelaksanaan}

Adapun tahapan dalam pelaksanaan kegiatan pelatihan ini adalah sebagai berikut:

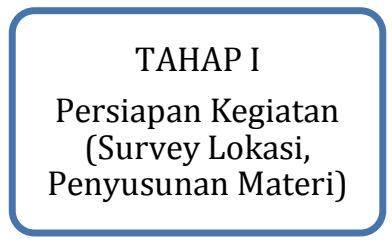

\section{TAHAP II}

Pemberian Materi SPM \& Leadership
TAHAP III

Diskusi Materi serta

Tanya Jawab

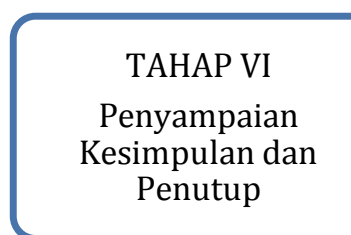

TAHAP V

Diskusi Hasil

Pelatihan, Pemberian

Saran dan

Rekomendasi
TAHAP IV

Pemberian Pelatihan Penyusunan Pembukuan Akuntansi, Pengendalian Internal dan Teknik Kepemimpinan

Gambar 1. Tahapan Pelaksanaan Kegiatan Pelatihan 


\section{HASIL DAN PEMBAHASAN}

Kegiatan pelatihan sistem pengendalian manajemen dan leadership dalam meningkatkan pengetahuan keorganisasian serta kinerja bagi organisasi informal telah dilaksanakan pada tanggal 5-6 Mei 2018 bertempat di SD Muhammadiyah Balayudha 6/14 Palembang. Kegiatan pelatihan berjalan dengan lancar dan sesuai dengan rencana. Kegiatan ini dihadiri oleh 30 orang dari beberapa organisasi informal di Kota Palembang, peserta didominasi dari organisasi penggiat seni. Peserta pelatihan terlihat antusias terhadap kegiatan ini khususnya materi-materi yang disampaikan. Peserta pelatihan juga mengikuti acara ini selama dua hari dari awal sampai dengan selesai.

Pada hari pertama disampaikan mengenai materi pembukuan akuntansi. Materi yang disampaikan dari penjelasan siklus akuntansi, saldo normal akuntansi, pencatatan transaksi, sampai dengan pembuatan laporan keuangan yang benar. Semua peserta sangat antusias dengan materi tersebut, terbukti dengan banyaknya peserta yang bertanya pada saat sesi tanya jawab berlangsung. Semua pertanyaan dibahas sampai selesai dan dapat dimengerti oleh peserta. Pada hari selanjutnya atau hari kedua, materi yang disampaikan mengenai materi pengendalian internal. Materi ini membahas tentang bagaimana melakukan pengendalian agar memperkecil salah saji dan menghindari terjadinya fraud(kecurangan). Pada sesi Tanya jawab materi tersebut banyak peserta yang menceritakan pengalamannya di organisasinya dalam melakukan pengendalian internal. Banyak yang semakin paham bahwa pengendalian internal dalam organisasi sangatlah penting guna kelangsungan organisasi. Materi yang terakhir mengenai teknik leadership (kepemimpinan), materi ini juga mendapatkan respon yang baik serta menarik perhatian peserta karena jika salah dalam menggunakan teknik leadership maka organisasi tidak akan berjalan sesuai dengan tujuan organisasi.

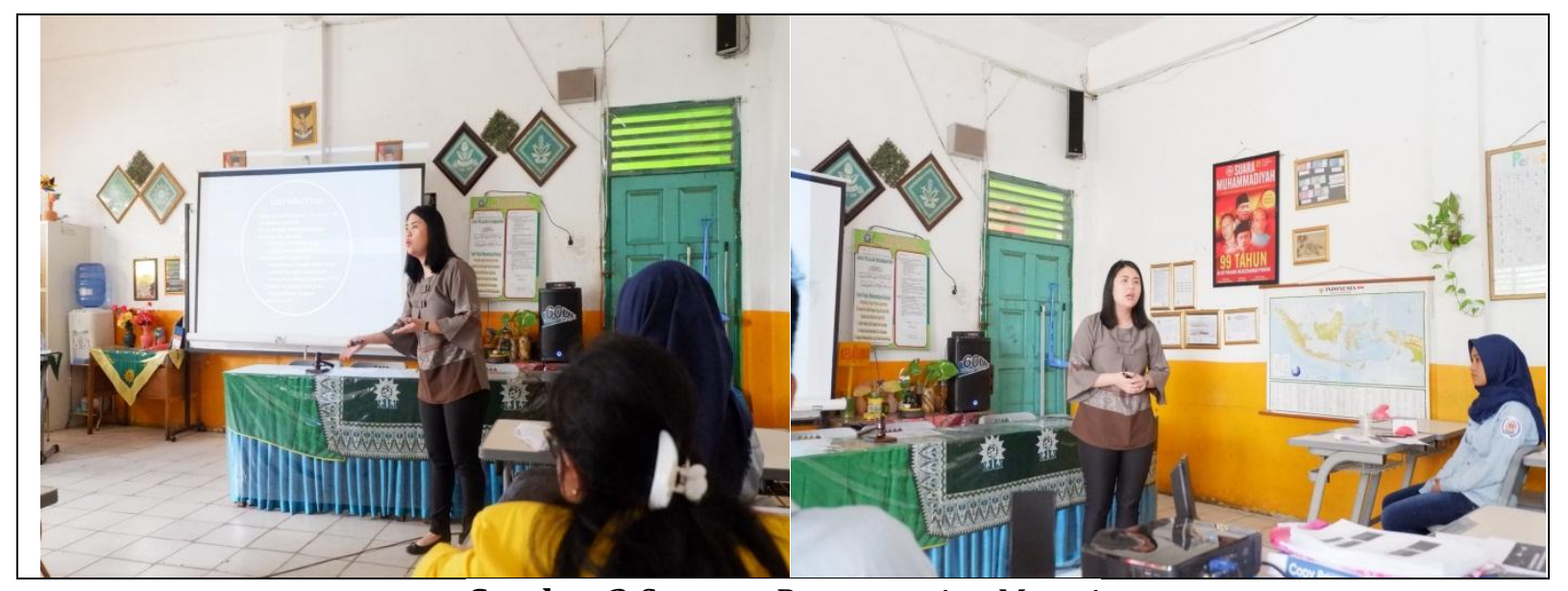

Gambar 2.Suasana Penyampaian Materi

Semua materi telah disampaikan dan diskusi melalui tanya jawab selanjutkan dibentuk group discussion untuk membahas kasus-kasus organisasi yang telah disiapkan oleh pembicara serta terdapat beberapa masalah yang harus diselesaikan yang tentunya berkaitan dengan materi yang telah disampaikan. Semua group berdiskusi, lalu menyusun laporan keuangan yang baik, mencari solusi atas masalah pengendalian internal serta memilih teknik kepemimpinan seperti apa agar kasus tersebut terselesaikan dengan baik. Setelah kasus diselesaikan maka dilakukan diskusi keseluruhan dan dibahas satu per satu kasus yang ada serta dilakukan evaluasi, pemberian saran dan rekomendasi terhadap kasus tersebut.

Berdasarkan hasil kegiatan pelatihan ini tingkat pemahaman peserta mengalami peningkatan, terbukti dari hasil diskusi kasus serta pemecahan masalah dan pencarian solusi yang dipaparkan oleh peserta sudah sesuai dengan materi yang disampaikan sebelumnya. Hasil diskusi dan materi yang disampaikan besar harapan diterapkan oleh peserta pada organisasi tempat mereka bernaung sehingga organisasi tersebut lebih terstruktur dan tertata agar dapat mencapai tujuan organisasi dengan baik. 


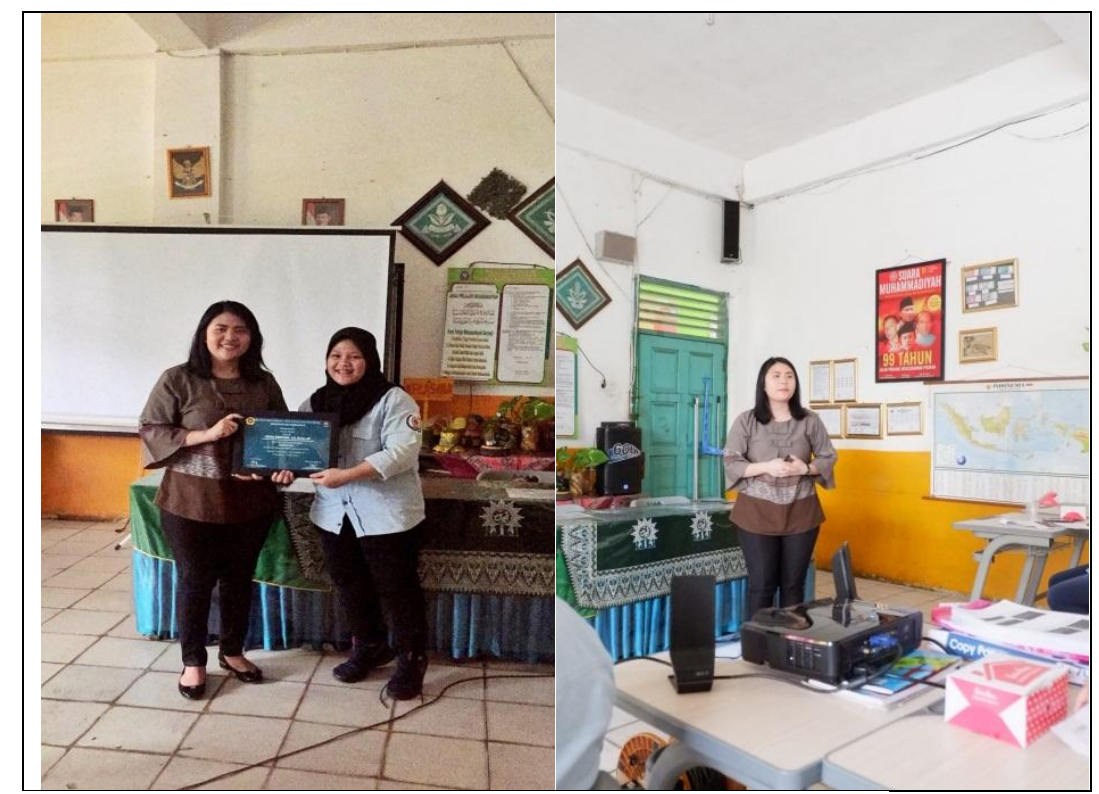

Gambar 3.Penyerahan Sertifikat dan Sesi Tanya Jawab

\section{KESIMPULAN}

Kesimpulan yang didapat dari kegiatan pengabdian masyarakat kepada pengurus organisasi informal di Kota Palembang adalah sebagai berikut:

1. Penyusunan pembukuan administrasi dan keuangan organisasi harus dilakukan secara benar agar terhindar dari salah saji.

2. Kegiatan pengendalian internal harus selalu dilakukan untuk menghindari terjadinya fraud (kecurangan).

3. Menentukan teknik leadership (kepemimpinan) sangat berpengaruh dalam menjalankan suatu organisasi karena berhubungan erat dengan perilaku individu semua anggotanya.

4. Materi dan hasil diskusi pada kegiatan pengabdian ini diharapkan dapat membantu pengurus organisasi dalam menjalankan organisasi dengan baik dan benar sesuai dengan tujuan organisasi.

5. Kegiatan ini mendapatkan respon yang baik dari para pengurus organisasi serta terlaksana dengan lancar sesuai dengan rencana dan tujuan.

6. Kegiatan ini memberikan value added, pengetahuan keorganisasian serta meningkatkan kinerja bagi pengurus dan anggota organisasi.

\section{UCAPAN TERIMA KASIH}

Ucapan terimakasih diberikan kepada Universitas Indo Global Mandiri selaku pelindung dalam kegiatan ini, Ketua Umum Imasfek Unsri beserta pengurus yang telah membantu menyelenggarakan kegiatan ini dan semua peserta yang telah memberikan waktunya untuk kegiatan pelatihan ini. Semoga kegiatan pengabdian ini memberikan manfaat bagi kita semua.

\section{DAFTAR PUSTAKA}

Halim, Abdul dkk, 2000, Sistem Pengendalian Manajemen, Unit Penerbit dan Percetakan Akademik Manajemen Perusahaan YKPN, Yogyakarta.

Onong, Effendy, 2003, Ilmu, Teori, Dan FilsafatKomunikasi, Penerbit Citra Aditya, Bandung. Supriyono, R.A, 2000. Sistem Pengendalian Manajemen, Edisi Pertama, Penerbit BPFE-Yogyakarta, Yogyakarta.

Winardi, J, 2003, Teori Organisasi dan Pengorganisasian, Edisi 1, Penerbit PT RajaGrafindo Persada, Jakarta. 